\title{
Modified soluble dietary fiber from black bean coats with its rheological and bile acid binding properties
}

Ziqian Feng ${ }^{\mathrm{a}}$, Wei Dou ${ }^{\mathrm{a}}$, Sierkemideke Alaxi ${ }^{\mathrm{a}}$, Yuge Niu ${ }^{\mathrm{a},{ }^{*}}$, Liangli (Lucy) $\mathrm{Yu}^{\mathrm{b}}$.

${ }^{a}$ Institute of Food and Nutraceutical Science, School of Agriculture and Biology, Shanghai Jiao Tong University, Shanghai 200240, China

${ }^{b}$ Department of Nutrition and Food Science, University of Maryland, College Park, Maryland 20742, United States

* Corresponding Author:

Yuge Niu, Ph.D. Tel: (86)-21-34204538; fax: (86)-21-34204107; E-mail:

yugeniu@sjtu.edu.cn 


\section{ABSTRACT}

Alkaline hydrogen peroxide (AHP) was investigated to enhance the content and functionality of soluble dietary fiber (SDF) extracted from black bean coats. Compared with the content of SDF of original black bean coat $7.8 \%$, the content of SDF of modified black bean coat was $16.9 \%$ after treated by $15 \% \mathrm{H}_{2} \mathrm{O}_{2}(\mathrm{v} / \mathrm{v})$ at $\mathrm{pH} 11$ and 1:18 (w/v) as liquid-to-solid ratio for $0.5 \mathrm{~h}$. Monosaccharide composition confirmed that the ratio of galacturonic acid in modified SDF (M-SDF) was higher than that of original SDF (O-SDF), and M-SDF was also with smaller molecular weight $(\mathrm{Mw})$ of $1.24 \times 10^{6} \mathrm{Da}$ and lower $\zeta$-potential of $-42.3 \mathrm{mV}$. Other structural characters were determined by FT-IR and TEM. In the range of 2-6\% (w/v), both O-SDF and M-SDF showed a shear thinning behavior. The latter showed stronger gelation ability at the presence of $\mathrm{Ca}^{2+}$ evaluated by dynamic oscillatory rheometry. Moreover, M-SDF exhibited good abilities of binding bile acids in vitro. It could be concluded that M-SDF had a great potential to be applied as a novel kind of functional ingredient or additive in food industry.

Keywords: Black bean coats; Soluble dietary fiber; AHP; Rheology; Bile acid binding 


\section{Introduction}

Black bean has been widely used as nutrient-rich food and described in Compendium of Materia Medica. Its coat was a kind of byproduct during the process of black bean oil production. Black bean coats were rich in many natural compounds, such as polysaccharides, proteins, flavonoids, saponins and polyphenols (Guajardo-Flores, García-Patiño, Serna-Guerrero, Gutiérrez-Uribe , \& Serna-Saldívar, 2012; Todd \& Vodkin, 1993; Choung et al., 2001; Jiang et al., 2014). It was demonstrated that the black bean coat extract could prevent obesity and diabetes by enhancing energy expenditure and suppressing inflammation (Kanamoto et al., 2011). However, most current researches are focusing on flavonoids, saponins or polyphenols of black beans coats. Other main functional fractions, such as dietary fiber, have been barely reported.

Dietary fiber (DF) has drawn a great attention because of its significant benefits, such as reducing the risk of coronary heart diseases, strokes, hypertension, diabetes, obesity, and certain gastrointestinal diseases (Elleuch et al., 2011; Huang, Ye, Chen, \& $\mathrm{Xu}, 2013$ ). DF could be classified into insoluble (IDF) and soluble dietary fiber (SDF) based on whether it could form a dispersion or not when mixed with water (Jiménez-Escrig \& Sánchez-Muniz, 2000). Compared to IDF, SDF had certain better physiological and bioactive properties, such as stronger antioxidant activity, higher capacity to form gels, greater fermentability and viscosity (Esposito et al., 2005; Mateos-Aparicio, Mateos-Peinado, \& Rupérez, 2010; Feng et al., 2014; Galisteo, Duarte, \& Zarzuelo, 2008). Thus SDF could be readily applied to food products as thickeners, emulsifiers, stabilisers, and fat replacers (Cui, Wu, \& Ding, 2013; Sozer, Cicerelli, Heiniö, \& Poutanen, 2014).

Our previous study showed that black bean coats had dietary fibers as $69.2 \%$, but only $7.8 \%$ were soluble. Thus, the objective of this study is to enhance the content of SDF from black bean coats, as well as develop the application of byproducts in food industry. AHP was chosen as the modification method in this study. The molecular 
weight, monosaccharide composition and $\zeta$-potential of M-SDF were determined. Its structure was also analyzed by FT-IR and TEM. In addition, the rheological and bile acid binding capacity were determined to demonstrate the gelling property and potential health benefits of M-SDF.

\section{Materials and methods}

\subsection{Materials}

Black bean coats were donated by Shanxi Qingyu Oil Company Limited (Shanxi, China). After carefully removing dusts, beans and grass blade, the coats were ground into powder (40 mesh) using a grinder. Standard monosaccharaides including rhamnose, fructose, and xylose were purchased from Tokyo Chemical Industry (Shanghai, China). Glucose, cholestyramine resin, cholic and chenodexycholic acids, nicotinamide adenine dinucleotide, diphorase, and nitro blue tetrazolium were purchased from Sigma-Aldrich (St. Louis, USA). Arabinose, fucose, mannose, glucuronic acid, galactose, galacturonic acid and 3- $\alpha$-hydroxysterol dehydrogenase were purchased from J\&K Chemical Technology (Beijing, China). Dextrans with different molecular weights were purchased from the National Institute for Food and Drug Control (Beijing, China). Heat-stable $\alpha$-amylase, protease, and amyloglucosidase solutions were purchased from Megazyme (Co. Wicklow, Ireland). Other reagents for analysis were of analytical grade and used without further purification.

\subsection{Modification of bean coats}

Based on our previous orthogonal experiment, AHP modification was conducted under the optimal conditions. Certain weight of black bean coats powder was firstly mixed with $15 \% \mathrm{H}_{2} \mathrm{O}_{2}(\mathrm{v} / \mathrm{v})$ solution as 1:18 liquid-to-solid ratio (w/v) under $\mathrm{pH} 11$, and the suspension was then stirred for $0.5 \mathrm{~h}$ by magnetic stirring. After reaction, the solid matters of suspension were collected by vacuum filtration followed by distilled 
water-washing twice. Finally, the washed solid was transferred to oven overnight at $60{ }^{\circ} \mathrm{C}$ to get the modified black bean coats for SDF extraction.

\subsection{Preparations of SDF from modified black bean coats}

The SDF was extracted by enzymatic-gravimetric procedure according to the AOAC method 985.29 (AOAC, 2001) with slight modifications. Six gram of original or modified black bean coats was dispersed in $240 \mathrm{~mL}$ MES-TRIS buffer ( $\mathrm{pH}$ 8.2) and mixed by magnetic stirring for $1 \mathrm{~h}$. Then the suspension was added with $300 \mu \mathrm{L}$ of $\alpha$-amylase solution, and hydrolyzed at $95{ }^{\circ} \mathrm{C}-100{ }^{\circ} \mathrm{C}$ under constant shaking for 35 min. After the temperature of the hydrolysate decreased to $60{ }^{\circ} \mathrm{C}, 600 \mu \mathrm{L}$ of protease solution was added for further hydrolysis under constant shaking for $30 \mathrm{~min}$. Next, the $\mathrm{pH}$ of mixture was adjusted to 4.5 by acetic acid $(3 \mathrm{M})$. Amyloglucosidase solution $(600 \mu \mathrm{L})$ was then added for final hydrolysis at $60{ }^{\circ} \mathrm{C}$ for 30 min under constant shaking. The ultimate hydrolysate was filtrated and the sediment was washed by distilled water twice. All the filtrate was collected and condensed to about one-tenth in vacuum rotary evaporation system. Afterwards, the concentrated filtrate was mixed with $95 \%(\mathrm{v} / \mathrm{v})$ ethanol at $60{ }^{\circ} \mathrm{C}$ for $1 \mathrm{~h}$ followed by centrifugation at $4500 \mathrm{rpm}$ for 10 min. Finally, the precipitated flocculate was subjected to vacuum freeze-drying to get SDF.

2.4 Monosaccharide composition

\subsubsection{Hydrolysis of SDF}

The SDF sample $(2.0 \mathrm{mg}$ ) was dissolved with $0.4 \mathrm{~mL}$ distilled water and then added $0.4 \mathrm{~mL}$ of $4 \mathrm{M}$ trifluoroacetic acid (TFA) in a sealed tube. The sealed tube was kept at $110{ }^{\circ} \mathrm{C}$ for $3 \mathrm{~h}$. After cooled to room temperature, methanol reagent was used to remove excessive acid by nitrogen-blow, which was repeated for three times. The dry sample was then dissolved with $1.0 \mathrm{~mL}$ distilled water.

\subsubsection{Preparation of monosaccharide standard solutions}


Stock standard solutions $(2.0 \mathrm{mg} / \mathrm{mL})$ were prepared by dissolving each standard monosaccharide in a mixture of water solution. Working monosaccharide standard solutions $(0.01 \mathrm{mg} / \mathrm{mL})$ for generating the calibration curve were further obtained by appropriate dilution of the stock standard solutions with distilled water. The sample solutions were filtered through $0.45 \mu \mathrm{m}$ syringe filters prior to use. All the solutions were stored at $4{ }^{\circ} \mathrm{C}$ until being used.

\subsubsection{Ion Chromatography}

The monosaccharide compositions of SDF were analyzed by HPAEC after acid hydrolysis. HPAEC was performed on a Dionex ICS-2500 system, equipped with PAD and a Carbo PACTM PA20 column $(3 \mathrm{~mm} \times 150 \mathrm{~mm})$. Hydrolysates $(25 \mu \mathrm{L})$ were infected for ion chromatography analyzed. The eluant was a mixture of three solutions: solution A: distilled water, solution B: $50 \mathrm{mM}$ sodium hydroxide solution and solution $\mathrm{C}$ : $0.5 \mathrm{M}$ sodium acetate solution. Elution was performed using a gradient (Table 1) that was optimized for efficiency and also provided specific quantitative analysis of neutral and acidic monosaccharides. The flow rate was adjusted to $0.45 \mathrm{~mL} / \mathrm{min}$ and the column temperature was set at $30^{\circ} \mathrm{C}$. The retention time of each monosaccharide standard in the mixtures was confirmed by the analysis of each monosaccharide.

Calibration was performed with a standard solution of L-rhamnose, L-arabinose, D-glucose, D-xylose, D-fructose, D-mannose, D-galactose, L-fucose, glucuronic acid and galacturonic acid. Data were processed using the Chromeleon software (Chromeleon 7.2, Dionex, USA).

\subsection{Molecular weight determination}

The molecular weight of SDF was determined using a high-performance size exclusion chromatograph (Agilent, USA) equipped with a gel filtration column (Shodex SUGAR KS-805, $8 \mathrm{~mm}$ i.d. $\times 300 \mathrm{~mm}$, Showa Denko, Japan) and a refractive index detector according to published method (Gong et al., 2015). In brief, 
distilled water was used as the mobile phase and eluted at a flow rate of $1.0 \mathrm{~mL} / \mathrm{min}$. The molecular weight of SDF was calculated by the standard curve (different dextrans molecular weight against its retention time) prepared with a series of dextran standards with different molecular weights (180, 2 700, 5 250, 9 750, 13 050, 36 800, 64 650, 135350,300600 and 2000000 Da, respectively).

\section{$2.6 \zeta$-potential determination}

The surface charges of O-SDF and M-SDF were measured using a particle analyzer (Zetasizer Nano ZS90, Malvern, UK). SDF solution $(2.0 \mathrm{mg} / \mathrm{mL})$ was placed in the folded capillary cell and sealed with two stoppers. Then the cell was mounted to determine the $\zeta$-potential of molecules. The output data indicated the charge of the SDF quantitatively. The $\zeta$-potential tests were performed by triplicate.

\subsection{Infrared spectral analysis}

The Fourier transform infrared (FT-IR) spectrum was carried out on a FT-IR spectrophotometer with an ATR accessory (Nicolet 6700, Thermo Fisher, USA) in the range of $4000-400 \mathrm{~cm}^{-1}$.

\subsection{Transmission electron microscope (TEM)}

To observe the microstructure, $0.01 \mathrm{mg} / \mathrm{mL}$ of SDF solution was prepared by distilled water. A droplet of SDF solution was deposited on the carbon film specimen (200 mesh, Beijing Zhongjingkeyi Technology, China). Transmission electron microscopy (Tecnai G2 Spirit BIOTWIN, FEI, USA) with an accelerating voltage of $120 \mathrm{kV}$ was applied to visualize the molecular morphology of the O-SDF and M-SDF samples after they were dried at ambient temperature and humidity.

\subsection{Rheological measurements}

\subsubsection{Instrument}


The rheological measurements were carried out by using an ARG2 rheometer (TA Instruments, USA) equipped with a SRS Peltier Circulator (TA Instruments, USA) as the temperature controller which made the temperature of the plate sensor system within $\pm 0.1{ }^{\circ} \mathrm{C}$ controllable. All the rheological studies were performed by using parallel plate (40 mm diameter with a gap of $500 \mu \mathrm{m})$.

\subsubsection{SDF solution preparation}

The SDF aqueous solutions were prepared as follow: $2 \%, 4 \%, 6 \%(\mathrm{w} / \mathrm{v})$ of samples was prepared with distilled water at $55^{\circ} \mathrm{C}$ under continuous magnetic stirring for $1 \mathrm{~h}$. After totally dissolved, the solutions were equilibrated at $4{ }^{\circ} \mathrm{C}$ overnight to allow the elimination of entrapped air.

\subsubsection{Flow behavior}

The appear viscosity was recorded by a function of shear rate ranging from 0.1 to $1000 \mathrm{~s}^{-1}$ acquired in a logarithmic ramp. All the experiments were performed duplicately at $25^{\circ} \mathrm{C}$ with 5 min equilibration before each rheological test.

\subsubsection{Preparation of gels}

The $1 \%(\mathrm{w} / \mathrm{v})$ SDF dispersion was prepared with distilled water by magnetic stirring. The dispersion was heated continuously up to $90{ }^{\circ} \mathrm{C}$ and the necessary amount of $50 \mathrm{mM}$ or $60 \mathrm{mM} \mathrm{CaCl}_{2}$ stock solution was added at the end of the heating. Then, the hot solutions were poured onto the preheated fixture of the rheometer $\left(90^{\circ} \mathrm{C}\right)$ immediately after preparation.

\subsubsection{Oscillatory dynamic tests}

After poured onto the rheometer plate, SDF gels were equilibrated for $2 \mathrm{~min}$ before tested. A few drops of water were placed at the cone's edge to avoid the evaporation of the sample during measurements. Gel formation of SDF samples with different concentrations of $\mathrm{Ca}^{2+}$ was investigated under a controlled cooling from 90 ${ }^{\circ} \mathrm{C}$ to $25^{\circ} \mathrm{C}$ at a rate of $1{ }^{\circ} \mathrm{C} / \mathrm{min}$. After that, a gel cure test was run at $1 \mathrm{rad} / \mathrm{s}$ and $25^{\circ} \mathrm{C}$ during $30 \mathrm{~min}$. Then, a frequency sweep at $25{ }^{\circ} \mathrm{C}$ from 0.1 to $100 \mathrm{rad} / \mathrm{s}$ was carried 
out at a constant strain (1\%). Finally, strain sweeps were performed at a constant frequency $(1 \mathrm{rad} / \mathrm{s})$ to verify that all the measurements could be completed within the region of linear viscoelasticity. All the oscillatory dynamic tests were performed by duplicate.

\subsection{Bile acid binding capacity}

According to a previous study (Niu, Xie, Zhang, Sheng, \& Yu, 2013), the bile acid binding capacities of M-SDF samples with different concentrations of $\mathrm{CaCl}_{2}$ were determined. Each sample ( $25 \mathrm{mg}$ ) was mixed with $500 \mu \mathrm{L}$ different concentrations of $\mathrm{CaCl}_{2}$. To simulate gastric conditions, the mixture was treated with $0.25 \mathrm{~mL}$ of $\mathrm{HCl}$ (0.01 M) followed by incubation at $37{ }^{\circ} \mathrm{C}$ with continuous shaking for $1 \mathrm{~h}$. $\mathrm{NaOH}$ solution $(0.1 \mathrm{M})$ was used to adjust the $\mathrm{pH}$ of mixture to 7.0 , and then $1.25 \mathrm{~mL}$ of bile acid stock solution (400 $\mu \mathrm{M}$ in $0.01 \mathrm{M}$ phosphate buffer, $\mathrm{pH} 7.0)$ was added to simulate intestinal conditions. The reaction mixture was incubated for $1 \mathrm{~h}$ at $37^{\circ} \mathrm{C}$. The supernatant was collected for bile acid assay after centrifugation for $10 \mathrm{~min}$ at $4500 \mathrm{rpm}$. Bile acid determination was determined by calculating the unbound bile acids quantitatively by a commercial kit from Sigma-Aldrich (St. Louis, MO, USA). The supernatant of reaction solution or bile acid standard $(100 \mu \mathrm{L})$ was added with $125 \mu \mathrm{L}$ of nicotinamide adenine dinucleotide $(2.5 \mathrm{mM}), 125 \mu \mathrm{L}$ of nitro blue tetrazolium (0.61mM), $100 \mu \mathrm{L}$ of 3- $\alpha$ hydroxysterol dehydrogenase (625 units/L), and $100 \mu \mathrm{L}$ of diphorase (625 units/L) as the final assay mixture. After incubation for $1 \mathrm{~h}$ at room temperature, $100 \mu \mathrm{L}$ of phosphoric acid $(1.33 \mathrm{M})$ was added to stop the reaction. The absorbance of each reaction mixture was measured at $530 \mathrm{~nm}$ with cholestyramine resin as a positive control. The levels of unbound bile acids were determined by standard curves of cholic and chenodeoxycholic acids, respectively. The bile acid binding capacity (mg/g sample) was calculated against $0.01 \mathrm{M}$ phosphate buffer ( $\mathrm{pH}$ 7.0). Triplication tests were taken for each sample against each bile acid. 


\subsection{Statistical analysis}

All the results were expressed as mean \pm standard deviation (SD). Data were analyzed by one-way analysis of variance (ANOVA) and least significant difference (LSD) using SAS 9.3 TS level 1M2 (SAS Institute Inc., USA). Statistical significance was declared at $P<0.05$.

\section{Results and discussion}

\subsection{SDF from black bean coats by AHP modification}

Compared with the content of SDF of original black bean coat $7.8 \%$, the content of SDF of modified black bean coat increased to $16.9 \%$ (shown in supporting material Fig. S), which indicated the method established in this study is of great efficiency in enhancing the SDF content of black bean coats. It is well known that the physical properties of dietary fibers could be altered dramatically by treatment with alkaline hydrogen peroxide (AHP), because AHP could reduce cellulose crystallinity as a solubilizing part of the lignin through rupture of the hydrogen bonding in the molecular chains, leading to more open internal structure in fibers. Thus, AHP could increase content of SDF in products and growth in the water retention, swelling capacity and sensory characteristics of modified dietary fibers as well (Larrea, Grossmann, Beléia, \& Tavares, 1997; Cao et al., 2016). In this study, AHP was selected as the modified method because of its great safety and good applicability in food industry.

\subsection{Structural characters of SDF}

\subsubsection{Monosaccharide composition of SDF}

Monosaccharide composition analysis by HPAEC (Table 2) showed that both O-SDF and M-SDF were composed of eight kinds of monosaccharide: galacturonic acid, fucose, glucose, rhamnose, arabinose, xylose, galactose and mannose. Among 
these monosaccharide, xylose, mannose, galactose, rhamnose, arabinose and galacturonic acid are the mainly typical compositions of hemicellulose in most plant cell walls. The result indicated that hemicellulose was one of the main components of black bean coats. On the other hand, the amount of galacturonic acid was also high in both O-SDF and M-SDF SDF. As galacturonic acid was one of the major pectic monosaccharides in pectin (Lira-Ortiz et al., 2014), another major component of SDF from black bean coats may be pectin. Compared to the O-SDF, there was a significant decrease in the amount of galactose and mannose, and also an obvious increase in the content of pentose (arabinose and xylose) and galacturonic acid in the M-SDF, which may indicate an oxidizing reaction on polysaccharides induced by AHP.

\subsubsection{Molecular weight of SDF}

Both of HPLC spectrogram of O-SDF and M-SDF showed one main peak with $84.0 \%$ peak area and other three small peaks. The molecular weight was calculated as $1.44 \times 10^{6} \mathrm{Da}$ for O-SDF and $1.24 \times 10^{6} \mathrm{Da}$ for M-SDF using a dextran standard curve. The decrease in molecular weight could be explained by the oxidation of AHP, which implied that AHP treatment could severely degrade the structure of SDF.

\subsubsection{FT-IR and $\zeta$ - potential of SDF}

FT-IR spectra have been utilized to elucidate the functional groups of polymers, as well as the bonding information of these functional groups. The FT-IR spectrum was shown in Fig. 1. The general spectral profiles of the O-SDF and M-SDF were similar except some characteristic bands. A broad band located at about $3441 \mathrm{~cm}^{-1}$ both in M-SDF and O-SDF was attributed to the O-H stretching of hydrogen bound of the hydroxyl groups mainly from cellulose and hemicellulose (Ma \& Mu, 2016). In addition, a significant reduction in intensity and width of the peak at $3441 \mathrm{~cm}^{-1}$ was observed in M-SDF, indicating the degradation of cellulose or hemicellulose due to AHP treatment. The weak band at $2925 \mathrm{~cm}^{-1}$ was originated from C-H stretching, which represented the presence of the typical structure of polysaccharide compounds (Yan, Ye, \& Chen, 2015). The typical peak at $1634 \mathrm{~cm}^{-1}$ was corresponded to 
characteristic bending or stretching of aromatic hydrocarbons of lignin (Zhao et al., 2013) which was another mainly component of dietary fiber. It was noteworthy that carbonyl group stretching of ester group (at $1733 \mathrm{~cm}^{-1}$ ) (Zhang, Liang, Pei, Gao, \& Zhang, 2009) was only observed in O-SDF, implying the oxidant effect of AHP. The signals at $800 \mathrm{~cm}^{-1}$ and $1200 \mathrm{~cm}^{-1}$ were resulted from the highly coupled C-C-O, $\mathrm{C}-\mathrm{OH}$ and $\mathrm{C}-\mathrm{O}-\mathrm{C}$ stretching vibrations of the polymer backbone (Mudgil, Barak, \& Khatkar, 2012; Shobha, Vishu Kumar, Tharanathan, Koka, \& Gaonkar, 2005).

The surface charge $(\zeta$ - potential) was examined to further explain the mechanism of gelation of M-SDF. The $\zeta$-potentials of O-SDF and M-SDF were -9.76 and -42.3 $\mathrm{mV}$, respectively. These data showed an over 4-fold increase of surface negative charge of the M-SDF compared to that of the original, indicating the stronger electrostatic forces between M-SDF and $\mathrm{Ca}^{2+}$ may be another essential reason for gelation in M-SDF apart from hydrogen bonding.

\subsubsection{Transmission Electron Microscopy of SDF}

The TEM images of O-SDF and M-SDF were showed in Fig.2. It was obvious that the SDF treated by AHP tended to form a network with more open internal structure, whereas the molecular morphology of O-SDF presented as chains with lots of branches. The different microscopic morphology between O-SDF and M-SDF could explain the improvements of water solubility, the ability of gel formation and the bile acid binding capacity after modification.

\subsection{Rheological properties}

\subsubsection{Flow properties}

The flow properties of SDF from black bean coats showed in Fig. 3, which illustrated the effect of shear rate on viscosity of different concentrations of SDF at 25 ${ }^{\circ} \mathrm{C}$. A shear thinning behavior was observed in both O-SDF and M-SDF at all concentrations. As for SDF of $6 \%(\mathrm{w} / \mathrm{v})$, a sharp and linear decrease of viscosity presented throughout. With the decrease of SDF concentration, the viscosity began to 
reduce slowly at high shear rates, especially for M-SDF. A decreasing number of chain entanglements could account for the decrease in viscosity at high shear rates (Qi, Cui, Chen, \& Guo, 2005). In addition, the viscosity of both O-SDF and M-SDF decreased as the reducing SDF concentration, and the viscosity of M-SDF decreased sharply when the concentration lowered to $4 \%$. Compared to O-SDF, M-SDF aqueous solution exhibited lower viscosity at each concentration.

\subsubsection{Gelling properties}

Since gelling properties had little significant difference among O-SDF with different concentrations of $\mathrm{Ca}^{2+}$, Fig 4 only showed the results of oscillatory dynamic test of O-SDF (1\%, w/v) in the presence of $7.5 \mathrm{mM} \mathrm{CaCl}_{2}$ as an example. Fig. $4 \mathrm{a}$ showed the variation of storage modulus $\left(G^{\prime}\right)$ and loss modulus $\left(G^{\prime \prime}\right)$ during controlled cooling. It was obvious that $\mathrm{G}^{\prime}$ and $\mathrm{G}^{\prime \prime}$ had similar variation trend and approximate value with strong temperature dependence, indicating gel formation did not occur in this system during cooling. At $25^{\circ} \mathrm{C}, \mathrm{G}^{\prime}$ and $\mathrm{G}^{\prime \prime}$ increased rapidly at beginning and reached a steady value after $500 \mathrm{~s}$ with the circular frequency of $1 \mathrm{rad} / \mathrm{s}$, indicating a stable system formed (Fig. 4b). Mechanical spectra of O-SDF-CaCl system showed in Fig. 4c after 30 min at a constant strain (1\%). G" increased linearly as increasing frequency, while there was an abrupt rise after $10 \mathrm{rad} / \mathrm{s}$ in $\mathrm{G}^{\prime}$, implying a sudden structural change in the system. The strain sweeping results (Fig. 4d) confirmed that all the measurements above were within the linear viscoelastic region.

The viscoelastic behavior of M-SDF solution at a concentration of $1 \%(\mathrm{w} / \mathrm{v})$ was investigated in the presence of $5,7.5$ and $10 \mathrm{mM} \mathrm{CaCl}_{2}$. Fig. 5a showed the semi-logarithmic plots of $\mathrm{G}^{\prime}$ and $\mathrm{G}^{\prime \prime}$ versus temperature which obtained at a constant frequency during controlled cooling. It revealed that a cross-linked network was formed in the presence of $\mathrm{CaCl}_{2}$, which was characterized by the temperature independence of $\mathrm{G}^{\prime}$ and $\mathrm{G}^{\prime \prime}$ on cooling. In fact, no crossover between $\mathrm{G}^{\prime}$ and $\mathrm{G}^{\prime \prime}$ occurred during cooling from $90{ }^{\circ} \mathrm{C}$ to $25^{\circ} \mathrm{C}$. All system showed a typical gel-like behavior $\left(\mathrm{G}^{\prime}>\mathrm{G}^{\prime \prime}\right)$, indicating that $\mathrm{Ca}^{2+}$ might act as a crosslink agent in the M-SDF solution. Also, $\mathrm{G}^{\prime}$ and $\mathrm{G}^{\prime \prime}$ increased with the enhancement of $\mathrm{Ca}^{2+}$ concentration. 
The time evolution of both $\mathrm{G}^{\prime}$ and $\mathrm{G}^{\prime \prime}$ moduli for M-SDF system was showed in Fig. $5 \mathrm{~b}$ at fixed frequency of $1 \mathrm{rad} / \mathrm{s}$ within linear viscoelastic region at $25^{\circ} \mathrm{C}$. Obviously, all systems appeared stable $\mathrm{G}^{\prime}$ and $\mathrm{G}^{\prime \prime}$ moduli during $30 \mathrm{~min}$ and presented a typical gel-like behavior. In the presence of $10 \mathrm{mM} \mathrm{CaCl}_{2}, \mathrm{G}$ ' reached almost $1000 \mathrm{~Pa}$ which was 200 -fold greater than that of $5 \mathrm{mM} \mathrm{CaCl}_{2}$.

Fig. 5c showed the mechanical spectra of $\mathrm{M}-\mathrm{SDF}-\mathrm{CaCl}_{2}$ system. The applied stress yielded $1 \%$ strain which was within the linear viscoelastic region. The M-SDF system with $7.5 \mathrm{mM}$ and $10 \mathrm{mM} \mathrm{CaCl}$ denoted a strong gel-like behavior, with $\mathrm{G}^{\prime}$ higher than $\mathrm{G}^{\prime \prime}$ and both of them with slight frequency dependence. Whereas, as for low concentration of $\mathrm{CaCl}_{2}(5 \mathrm{mM})$, the storage modulus $\left(\mathrm{G}^{\prime}\right)$ decreased sharply to negative value after frequency increased to $10 \mathrm{rad} / \mathrm{s}$, suggesting a structural collapse in this system. It was also noteworthy that the formed gels were soft and elastic rather than strong and hard gels.

The linear viscoelastic region of M-SDF gels was exhibited by the strain sweep. As shown in Fig. 5d, the linear viscoelastic region became narrower when calcium concentration increased. $\mathrm{G}^{\prime}$ of gel system with $5 \mathrm{mM} \mathrm{CaCl}_{2}$ remained constant until strain values reached $12 \%$. However, when strain values only increased to $6 \%, \mathrm{G}^{\prime}$ of M-SDF with $10 \mathrm{mM} \mathrm{CaCl}_{2}$ began to decrease dramatically. The strain at which $\mathrm{G}^{\prime}$ decreased sharply was defined as the critical strain S (Guo, Cui, Wang, Goff, \& Smith, 2009). At the critical strain S, gel structure began to collapse. Therefore, critical strain $\mathrm{S}$ reflected the deformability of a gel. The decreasing critical strain $\mathrm{S}$ value proved that M-SDF with high concentration of calcium obtained a greater deformability which could make it easier to process in food industry. In addition, all of systems had a critical strain $\mathrm{S}$ higher than $1 \%$. Thus, the selected strain (1\%) in the entire oscillatory dynamic experiments ensured that the gel network was not damaged by the imposed strain during the measurements.

According to the published study, the networks formed by calcium-pectin could be described as the egg-box model which $\mathrm{Ca}^{2+}$ was chelated between the carboxyl groups of different pectin chains (Powell, Morris, Gidley, \& Rees, 1982). Additionally, 
divalent ions gelation for pectin chains depended on the number of non-methylated galacturonic acid residues. (Mierczyńska, Cybulska, Sołowiej, \& Zdunek, 2015; Fang et al., 2008). Referring to the former monosaccharide composition, $\zeta$ - potential and TEM results, SDF modified by AHP was composed of pectin mainly with more galacturonic acid residues, carried much more negative charge and presented more open internal structure with plenty of porous structure than those of O-SDF. Therefore, the M-SDF showed more significant gel-forming property than the O-SDF. The gelation mechanism might be the contribution of hydroxyl groups via hydrogen bonds as well as ionic interactions between dissociated carboxyl groups via $\mathrm{Ca}^{2+}$-bridges.

\subsection{Bile acid binding capacity}

The ability of polymers to bind bile acids may enhance the elimination of bile acids and promote the conversion of cholesterol to bile acids in liver. It could reduce the levels of total plasma and LDL cholesterol and lower the risk of cardiovascular diseases as a result (Zhou, Xia, Zhang, \& Yu, 2006; Niu, Xie, Zhang, Sheng, \& Yu, 2013). As United States Food and Drug Administration claimed, it was allowable to make a cholesterol-lowering health statement for foods containing adequate amount of soluble fiber. As shown in Fig.6, M-SDF had remarkable binding capacities against both cholic (CA) and chenodeoxycholic acids (CDCA) at the present of $\mathrm{Ca}^{2+}$. The capacities enhanced as concentration of $\mathrm{Ca}^{2+}$ increased. The capacities at the highest concentration of $\mathrm{Ca}^{2+}$ were comparable with those of the resin which was a commercial drug to reduce plasma cholesterol level by the bile acid-binding mechanism. The study also proved that there was little bile acid binding capacity exhibited by O-SDF with or without $\mathrm{Ca}^{2+}$ as well as M-SDF without $\mathrm{Ca}^{2+}$ (data not shown). Thus, the significant bile acid binding capacity could be the result of the gel formed by SDF with $\mathrm{Ca}^{2+}$. As the concentration of $\mathrm{Ca}^{2+}$ increased, the growing amount of gel presented more open intern structure for bile acid binding, which was corresponding to the results of rheological properties discussed above. 


\section{Conclusion}

Alkaline hydrogen peroxide (AHP) was an efficient and safe modification method for improving the SDF content, rheological and functional properties of black beans coats. The content of SDF could be significantly increased from $7.8 \%$ to $16.9 \%$ under optimal AHP modified conditions. Compared to O-SDF, M-SDF had different ratio of monosaccharide composition, smaller molecular weight and higher surface negative charge. Both O-SDF and M-SDF aqueous solution exhibited a shear thinning behavior. However, the M-SDF showed greater gelation ability at the presence of $\mathrm{Ca}^{2+}$, which made it as a promising thickening and gelling additive in food applications. Moreover, the results of bile acid binding capacity suggested a high potential of modified SDF as cholesterol-lowering functional ingredient.

\section{Acknowledgements}

This work was partly supported by the National Science Foundation for Young Scholars of China (Grant No. 31401490), National High Technology Research and Development Program of China (Grant Nos. 2013AA102202; 2013AA102207); a special fund for Agro-scientific Research in the Public Interest (Grant No. 201203069) and a grant from Shanxi Qingyu Oil Co., Ltd. 


\section{References}

AOAC. (2001). Official methods of analysis (17th ed.). MD: Association of Official Analytical Chemists.

Cao, W. X., Sun, C., Qiu, J. P., Li, X. D., Liu, R. H., \& Zhang L. (2016). Pretreatment of sweet sorghum bagasse by alkaline hydrogen peroxide for enhancing ethanol production. Korean Journal of Chemical Engineering, 33(3), 873-879.

Choung, M. G., Baek, I. Y., Kang, S. T., Han, W. Y., Shin, D. C., Moon, H. P., et al. (2001). Isolation and determination of anthocyanins in seed coats of black soybean (Glycine max (L.) Merr.). Journal of Agricultural and Food Chemistry, 49(12), $5848-5851$.

Cui, S.W., Wu, Y., \& Ding, H. H. (2013). The range of dietary fibre ingredients and a comparison of their technical functionality. In J. A. Delcour, \& K. Poutanen (Eds.), Fibre-rich and Wholegrain Foods: Improving Quality (pp. 96-115). FL: Woodhead Publishing.

Elleuch, M., Bedigian, D., Roiseux, O., Besbes, S., Blecker, C., \& Attia, H. (2011). Dietary fibre and fibre-rich by-products of food processing: Characterisation, technological functionality and commercial applications: A review. Food chemistry, 124(2), 411-421.

Esposito, F., Arlotti, G., Maria Bonifati, A., Napolitano, A., Vitale, D., \& Fogliano, V. (2005). Antioxidant activity and dietary fibre in durum wheat bran by-products. Food Research International, 38(10), 1167-1173.

Fang, Y., Al-Assaf, S., Phillips, G. O., Nishinari, K., Funami, T., \& Williams, P. A. (2008). Binding behaviour of calcium to polyuronates: Comparison of pectin with alginate. Carbohydrate Polymers, 72(2), 334-341.

Feng, T., Su, Q., Zhuang, H., Ye, R., Gu, Z., \& Jin, Z. (2014). Ghost structures, pasting, rheological and textural properties between mesona blumes gum and various starches. Journal of Food Quality, 37(2), 73-82.

Galisteo, M., Duarte, J., \& Zarzuelo, A. (2008). Effects of dietary fibers ondisturbances clustered in the metabolic syndrome. The Journal of Nutritional 
Biochemistry, 19(2), 71-84.

Gong, L., Zhang, H., Niu, Y. G., Chen, L., Liu, J., Alaxi, S., et al. (2015). A Novel Alkali Extractable Polysaccharide from Plantago asiatic L. Seeds and Its Radical-Scavenging and Bile Acid-Binding Activities. Journal of Agricultural and Food Chemistry, 63(2), 569-577.

Guajardo-Flores, D., García-Patiño, M., Serna-Guerrero, D., Gutiérrez-Uribe, J. A., \& Serna-Saldívar, S. O. (2012). Characterization and quantification of saponins and flavonoids in sprouts, seed coats and cotyledons of germinated black beans. Food Chemistry, 134(3), 1312-1319.

Guo, Q., Cui, S. W., Wang, Q., Goff, H. D., \& Smith, A. (2009). Microstructure and rheological properties of psyllium polysaccharide gel. Food Hydrocolloids, 23(6), $1542-1547$.

Huang, Z., Ye, R., Chen, J., \& Xu, F. (2013). An improved method for rapid quantitative analysis of the insoluble dietary fiber in common cereals and some sorts of beans. Journal of Cereal Science, 57(3), 270-274.

Jiang, L. Z., Wang, J., Li, Y., Wang, Z. J., Liang, J., Wang, R., Chen, Y., et al. (2014). Effects of ultrasound on the structure and physical properties of black bean protein isolates. Food Research International 62, 595-601.

Jiménez-Escrig, A., \& Sánchez-Muniz, F. J. (2000). Dietary fibre from edible seaweeds: Chemical structure, physicochemical properties and effects on cholesterol metabolism. Nutrition Research, 20(4), 585-598.

Kanamoto, Y., Yamashita, Y., Nanba, F., Yoshida, T., Tsuda, T., Fukuda, I., et al. (2011). A black soybean seed coat extract prevents obesity and glucose intolerance by up-regulating uncoupling proteins and down-regulating inflammatory cytokines in high-fat diet-fed mice. Journal of Agricultural and Food Chemistry, 59(16), 8985-8993.

Larrea, M., Grossmann, M., Beléia, A., \& Tavares, D. (1997). Changes in water absorption and swollen volume in extruded alkaline peroxide pretreated rice hulls. Cereal Chemistry, 74(2), 98-101. 
Lira-Ortiz, A. L., Reséndiz-Vega, F., Ríos-Leal, E., Contreras-Esquivel, J. C., Chavarría-Hernández, N., Vargas-Torres, A., et al. (2014). Pectins from waste of prickly pear fruits (Opuntia albicarpa Scheinvar'Reyna'): Chemical and rheological properties. Food Hydrocolloids, 37, 93-99.

Ma, M. M., \& Mu, T. H. (2016). Effects of extraction methods and particle size distribution on the structural, physicochemical, and functional properties of dietary fiber from deoiled cumin. Food Chemistry, 194, 237-246.

Mateos-Aparicio, I., Mateos-Peinado, C., \& Rupérez, P. (2010). High hydrostatic pressure improves the functionality of dietary fibre in okara by-product from soybean. Innovative Food Science \& Emerging Technologies, 11(3), 445-450.

Mierczyńska, J., Cybulska, J., Solowiej, B., \& Zdunek, A. (2015). Effect of $\mathrm{Ca}^{2+}, \mathrm{Fe}^{2+}$ and $\mathrm{Mg}^{2+}$ on rheological properties of new food matrix made of modified cell wall polysaccharides from apple. Carbohydrate Polymers, 133, 547-555.

Mudgil, D., Barak, S., \& Khatkar, B. S. (2012). X-ray diffraction, IR spectroscopy and thermal characterization of partially hydrolyzed guar gum. International Journal of Biological Macromolecules, 50(4), 1035-1039.

Niu, Y. G., Xie, Z. H., Zhang, H., Sheng, Y., \& Yu, L. L. (2013). Effects of Structural Modifications on Physicochemical and Bile Acid-Binding Properties of Psyllium. Journal of Agricultural and Food Chemistry, 61(3), 596-601.

Powell, D. A., Morris, E. R., Gidley, M. J., \& Rees, D. A. (1982). Conformations and interactions of pectins: II. Influence of residue sequence on chain association in calcium pectate gels. Journal of Molecular Biology, 155(4), 517-531.

Qi, F., Cui, R. Q., Chen, C. P., \& Guo, B. N. (2005). Some completely monotonic functions involving polygamma functions and an application. Journal of Mathematical Analysis and Applications, 310(1), 303-308.

Shobha, M. S., Kumar, A. B. V., Tharanathan, R. N., Koka, R., \& Gaonkar, A. K. (2005). Modification of guar galactomannan with the aid of Aspergillus niger pectinase. Carbohydrate Polymers, 62(3), 267-273.

Sozer, N., Cicerelli, L., Heiniö, R.-L., \& Poutanen, K. (2014). Effect of wheat bran 
addition on in vitro starch digestibility, physico-mechanical and sensory properties of biscuits. Journal of Cereal Science, 60(1), 105-113.

Todd, J. J., \& Vodkin, L. O. (1993). Pigmented soybean (Glycine max) seed coats accumulate proanthocyanidins during development. Plant Physiology, 102, 663-670.

Yan, X. G., Ye, R., \& Chen, Y. (2015). Blasting extrusion processing: The increase of soluble dietary fiber content and extraction of soluble-fiber polysaccharides from wheat bran. Food Chemistry, 180, 106-115.

Zhang, M., Liang, Y., Pei, Y., Gao, W. W., \& Zhang, Z. S. (2009). Effect of Process on Physicochemical Properties of Oat Bran Soluble Dietary Fiber. Journal of Food Science, 74(8), C628-C636.

Zhao, X. Y., Chen, J., Chen, F. L., Wang, X. C., Zhu, Q. J., \& Ao, Q. (2013). Surface characterization of corn stalk superfine powder studied by FTIR and XRD. Colloids and Surfaces B: Biointerfaces, 104, 207-212.

Zhou, K. Q., Xia, W. S., Zhang, C., \& Yu, L. (2006). In vitro binding of bile acids and triglycerides by selected chitosan preparations and their physico-chemical properties. LWT-Food Science and Technology, 39(10), 1087-1092. 


\section{Table 1}

Ion chromatography gradient program for SDF samples analyzed.

\begin{tabular}{llll}
\hline Time (min) & Solvent A $(\%)$ & Solvent B $(\%)$ & Solvent C (\%) \\
\hline 0.0 & 95.0 & 5.0 & 0.0 \\
20.0 & 95.0 & 5.0 & 0.0 \\
20.1 & 85.0 & 5.0 & 10.0 \\
30.0 & 85.0 & 5.0 & 10.0 \\
30.1 & 0.0 & 100.0 & 0.0 \\
35.0 & 0.0 & 100.0 & 0.0 \\
\hline
\end{tabular}


Table 2

Monosaccharide composition of O-SDF and M-SDF.

\begin{tabular}{cccc}
\hline Area $(\%)$ & O-SDF & M-SDF & \\
\hline Ara & 3.42 & 20.29 & \\
Xyl & 1.52 & 15.10 & increased \\
Gal A & 16.24 & 29.59 & \\
Fuc & 0.43 & 2.95 & \\
Rha & 2.54 & 9.04 & decreased \\
Galac & 24.52 & 12.90 & \\
Man & 46.38 & 6.84 & \\
Glu & 4.94 & 3.29 & \\
\hline
\end{tabular}




\section{Figure captions}

Fig. 1. FTIR spectra of M-SDF (a) and O-SDF (b)

Fig. 2. TEM images of SDF in water solution: (a) O-SDF; (b) M-SDF.

Fig. 3. Viscosity curves of aqueous solution of soluble dietary fiber (SDF) at $2 \%$ (circles), 4\% (triangles) and 6\% (squares) (w/v): (a) O-SDF; (b) M-SDF.

Fig. 4. Oscillatory dynamic test results of O-SDF $(1 \%, w / v)$ in the presence of 7.5 $\mathrm{mM} \mathrm{CaCl}_{2}$. (a) $\mathrm{G}^{\prime}, \mathrm{G}^{\prime \prime}$ vs temperature $\left(\omega=1 \mathrm{rad} / \mathrm{s}\right.$, strain=1\%); (b) $\mathrm{G}^{\prime}, \mathrm{G}^{\prime \prime}$ vs time $\left(\omega=1 \mathrm{rad} / \mathrm{s}\right.$, strain=1\%, $\left.\mathrm{T}=25^{\circ} \mathrm{C}\right) ;(\mathrm{c}) \mathrm{G}^{\prime}, \mathrm{G}^{\prime \prime}$ vs angular frequency (strain=1\%, $\mathrm{T}=25$ $\left.{ }^{\circ} \mathrm{C}\right)$; (d) $\mathrm{G}^{\prime}$ vs strain $\left(\omega=1 \mathrm{rad} / \mathrm{s}, \mathrm{T}=25^{\circ} \mathrm{C}\right)$.

Fig. 5. Oscillatory dynamic test results of M-SDF (1\%, w/v) in the presence of $5 \mathrm{mM}$ (square), $7.5 \mathrm{mM}$ (circle) and $10 \mathrm{mM}$ (triangle) $\mathrm{CaCl}_{2}$. (a) $\mathrm{G}^{\prime}, \mathrm{G}^{\prime \prime}$ vs temperature $\left(\omega=1 \mathrm{rad} / \mathrm{s}\right.$, strain=1\%); (b) $\mathrm{G}^{\prime}, \mathrm{G}^{\prime \prime}$ vs time $\left(\omega=1 \mathrm{rad} / \mathrm{s}\right.$, strain=1\%, $\left.\mathrm{T}=25^{\circ} \mathrm{C}\right)$; (c) $\mathrm{G}^{\prime}$, $\mathrm{G}^{\prime \prime}$ vs angular frequency ( $\left.\operatorname{strain}=1 \%, \mathrm{~T}=25^{\circ} \mathrm{C}\right)$; (d) $\mathrm{G}^{\prime}$ vs strain $\left(\omega=1 \mathrm{rad} / \mathrm{s}, \mathrm{T}=25^{\circ} \mathrm{C}\right)$.

Fig. 6. Bile acid binding capacity of M-SDF in the presence of difference concentrations of $\mathrm{CaCl}_{2}$. Resin means cholestyramine resin, which is the positive control. Data are expressed as the mean \pm standard deviation (SD). Vertical bars represent the SD value of each data point. Values in the same acid treatment group with different letters were significantly different $(P<0.05)$.

Supplemental Material Fig. S Content of SDF from original and modified black bean coats. Data are expressed as the mean \pm standard deviation (SD). Vertical bars represent the SD value of each data point. Values carrying different letters were significantly different $(P<0.05)$. 
Fig. 1.

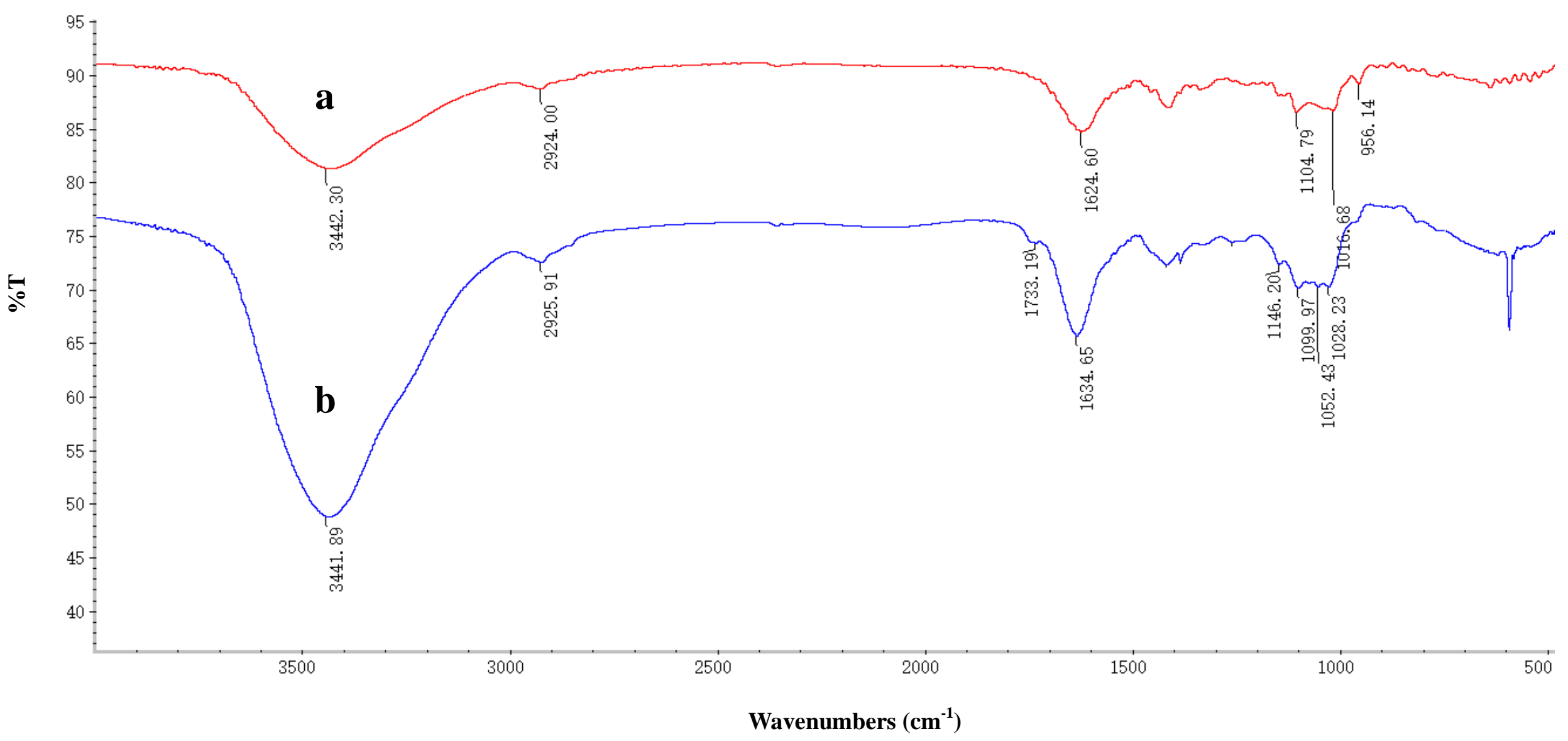


Fig. 2.

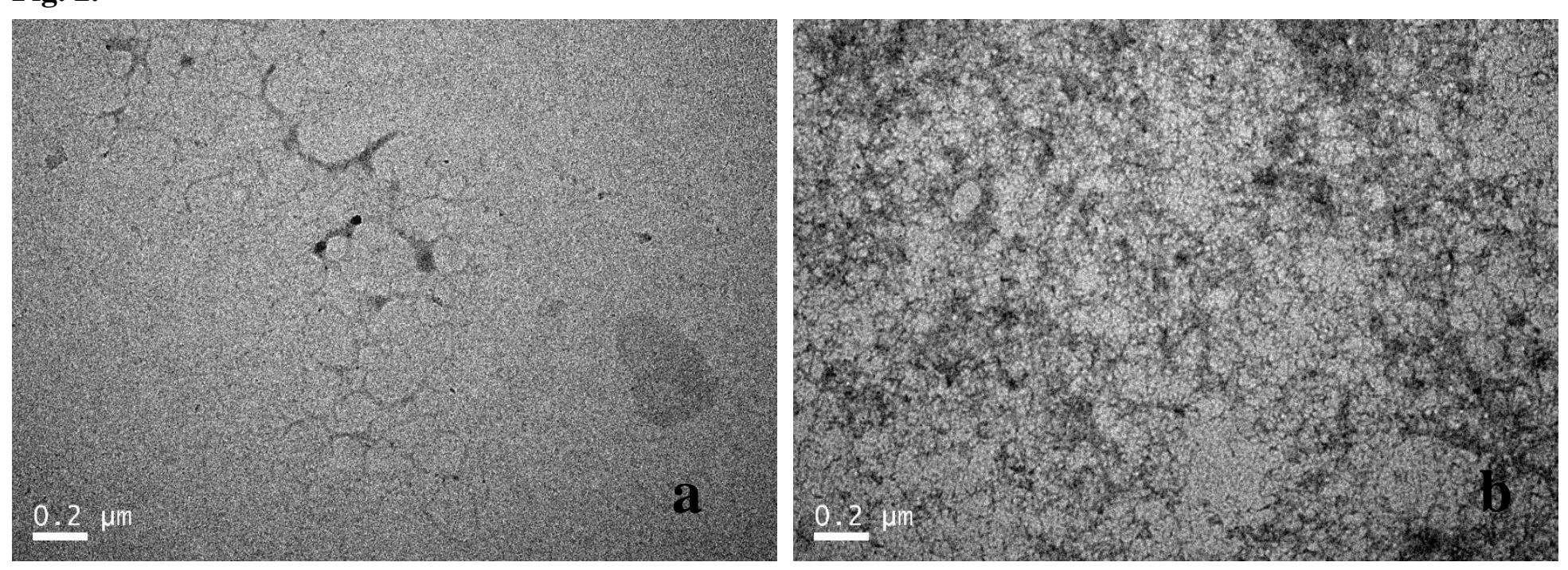


Fig. 3.

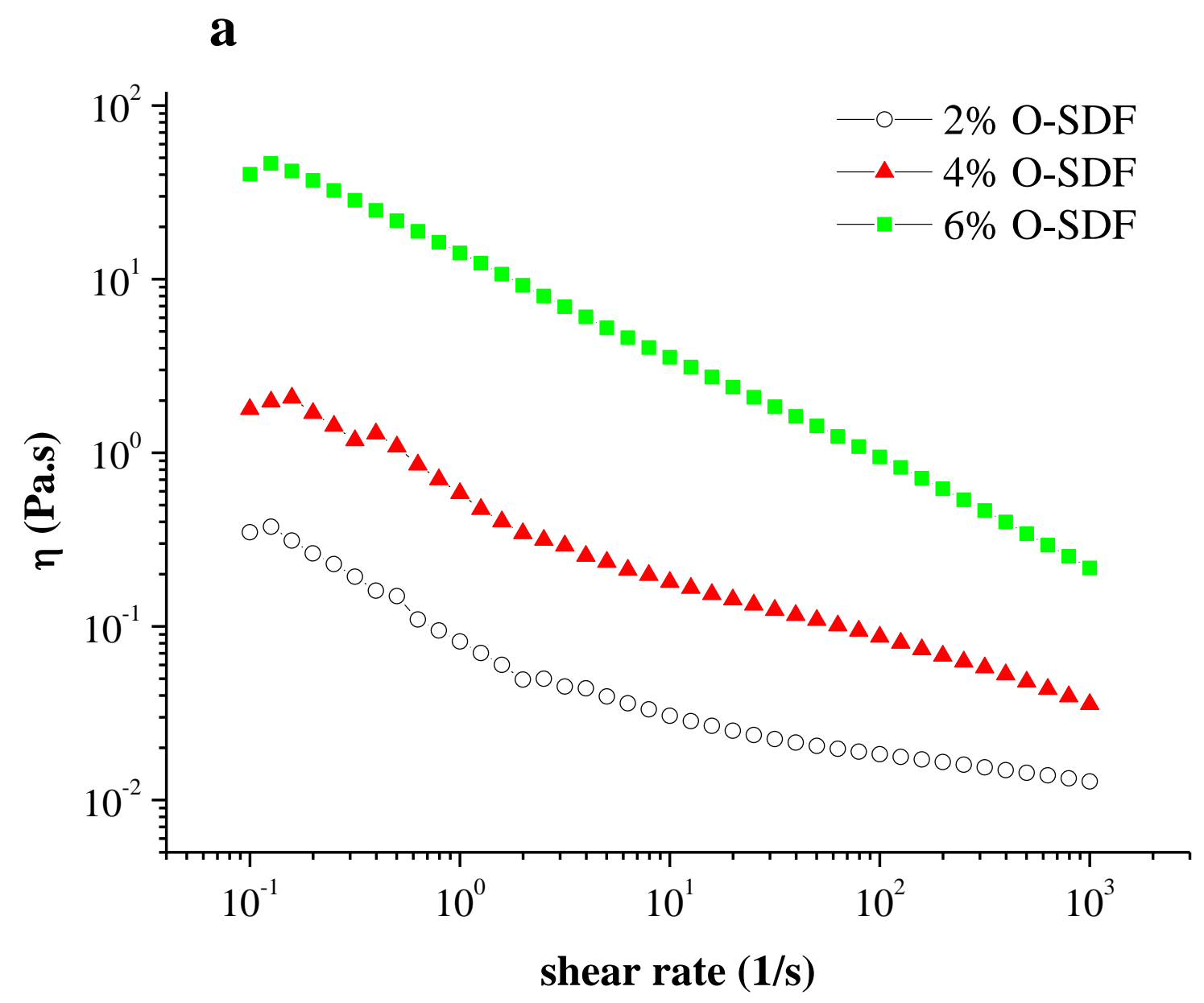




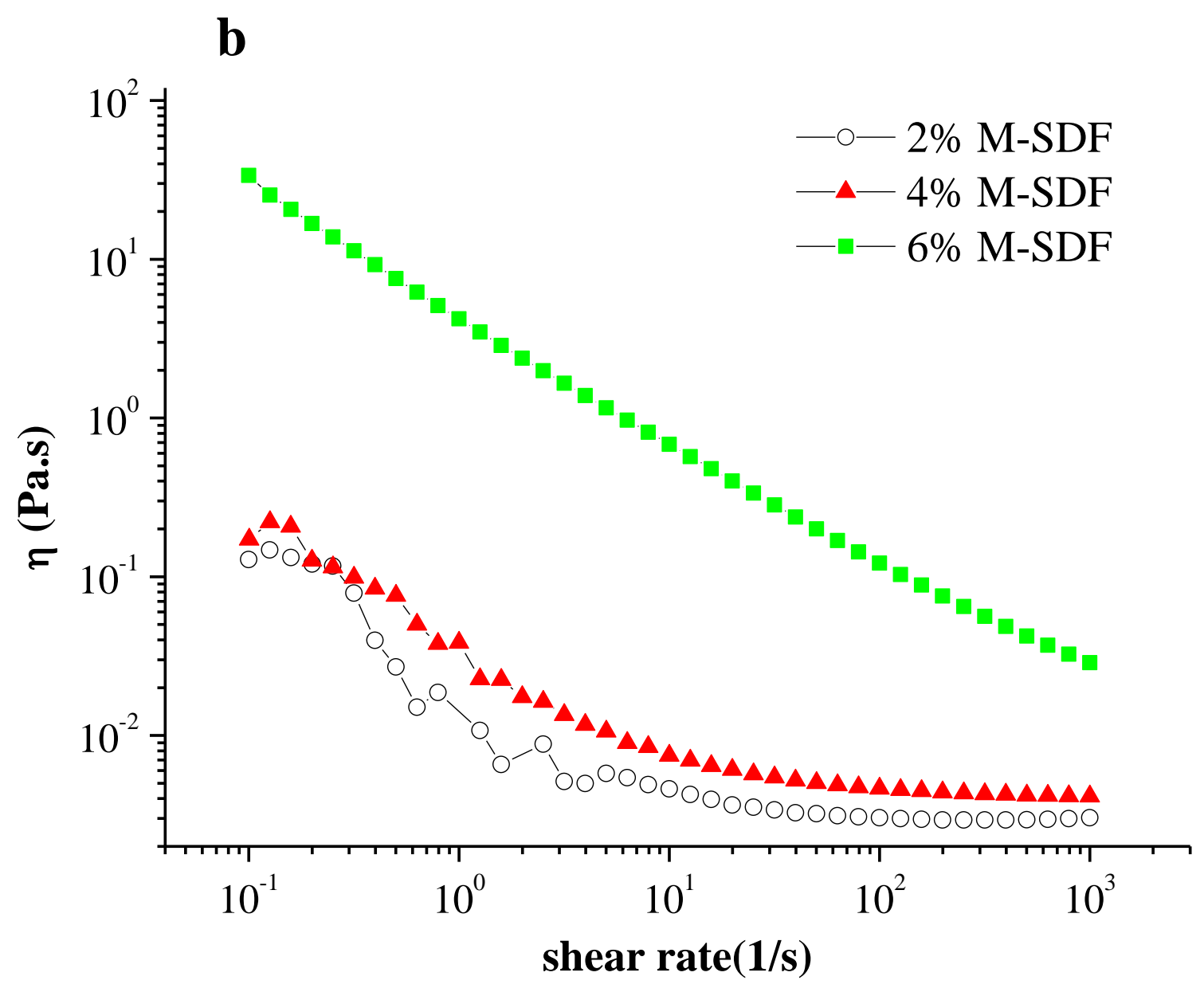


Fig. 4.

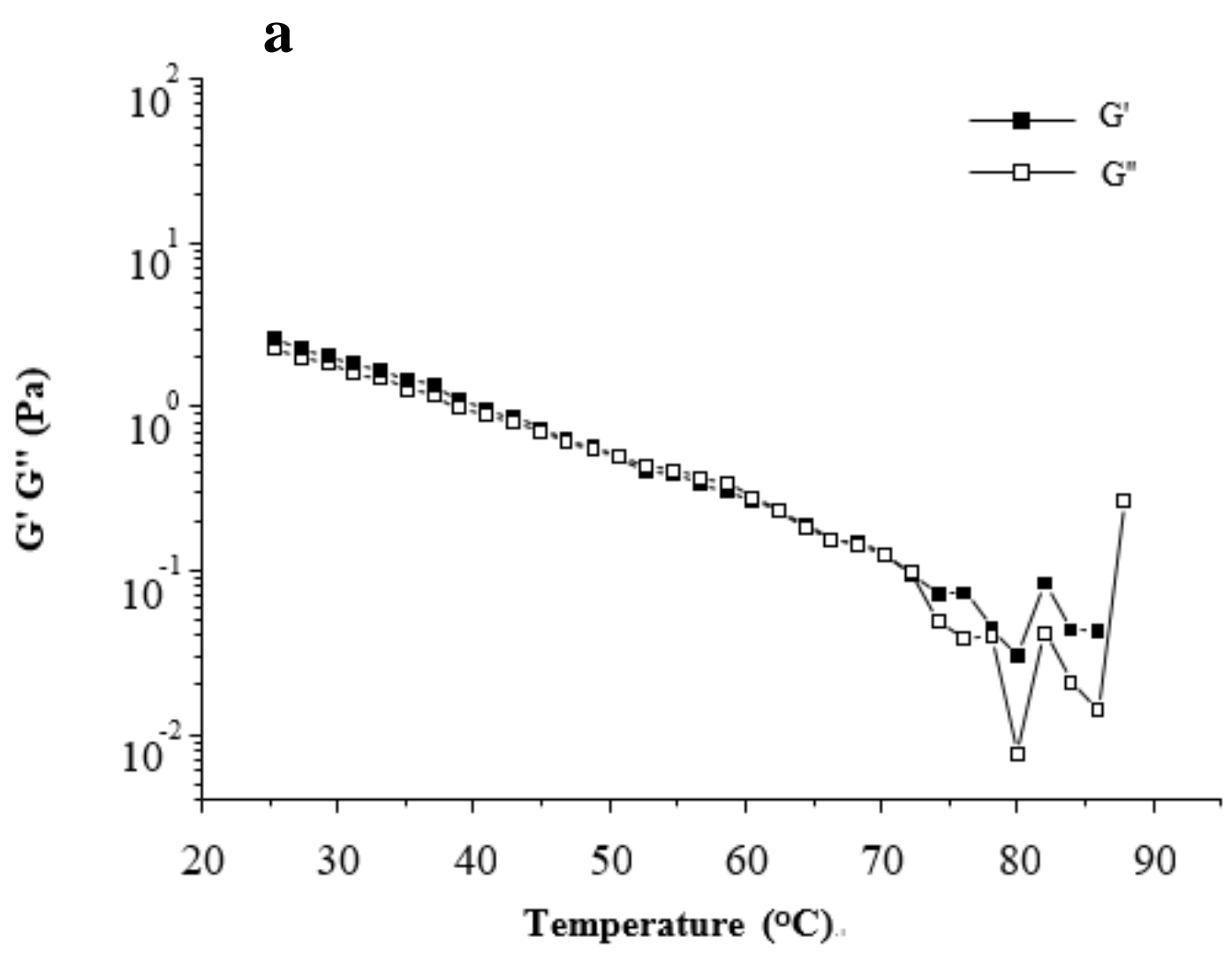




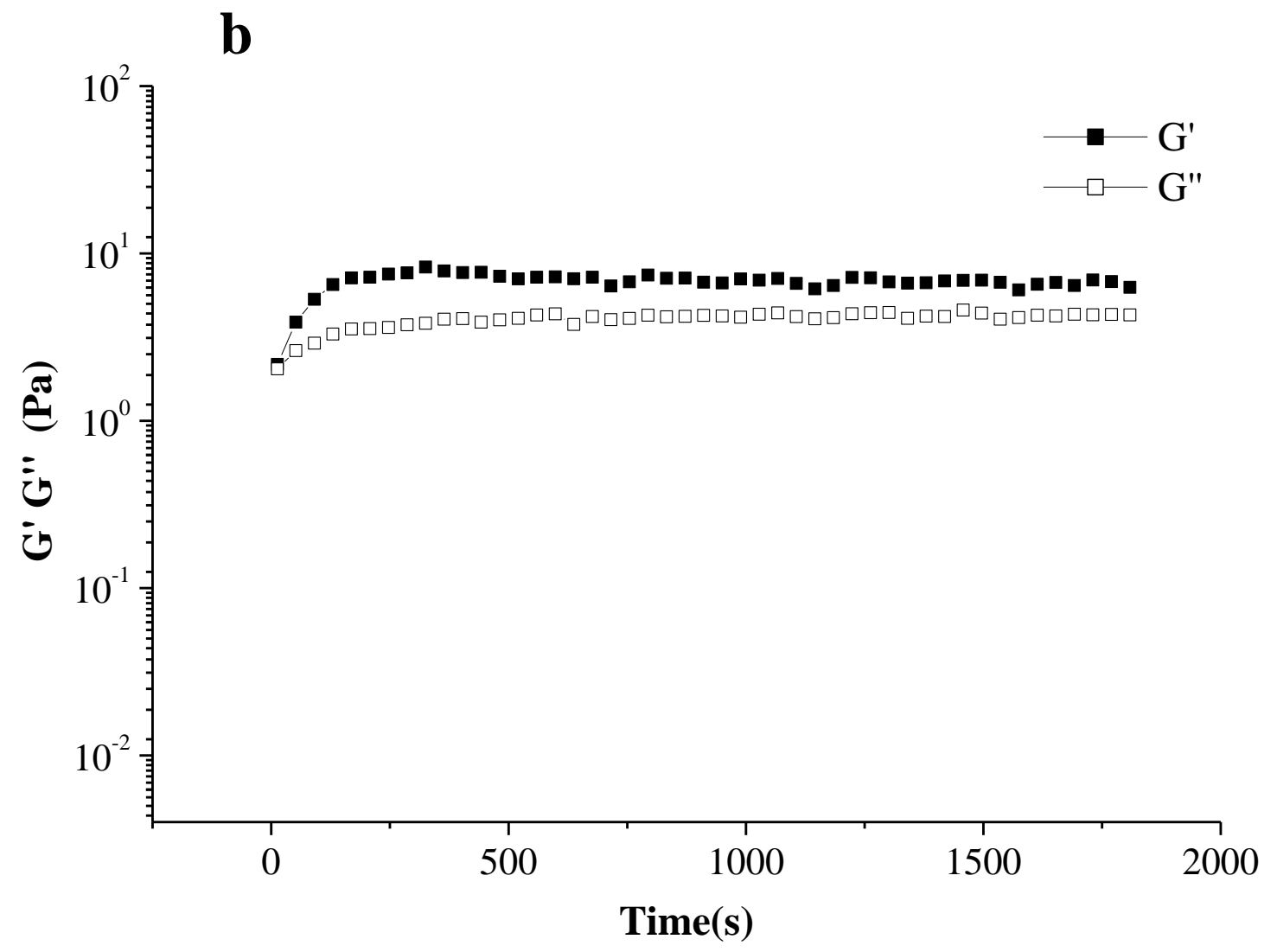




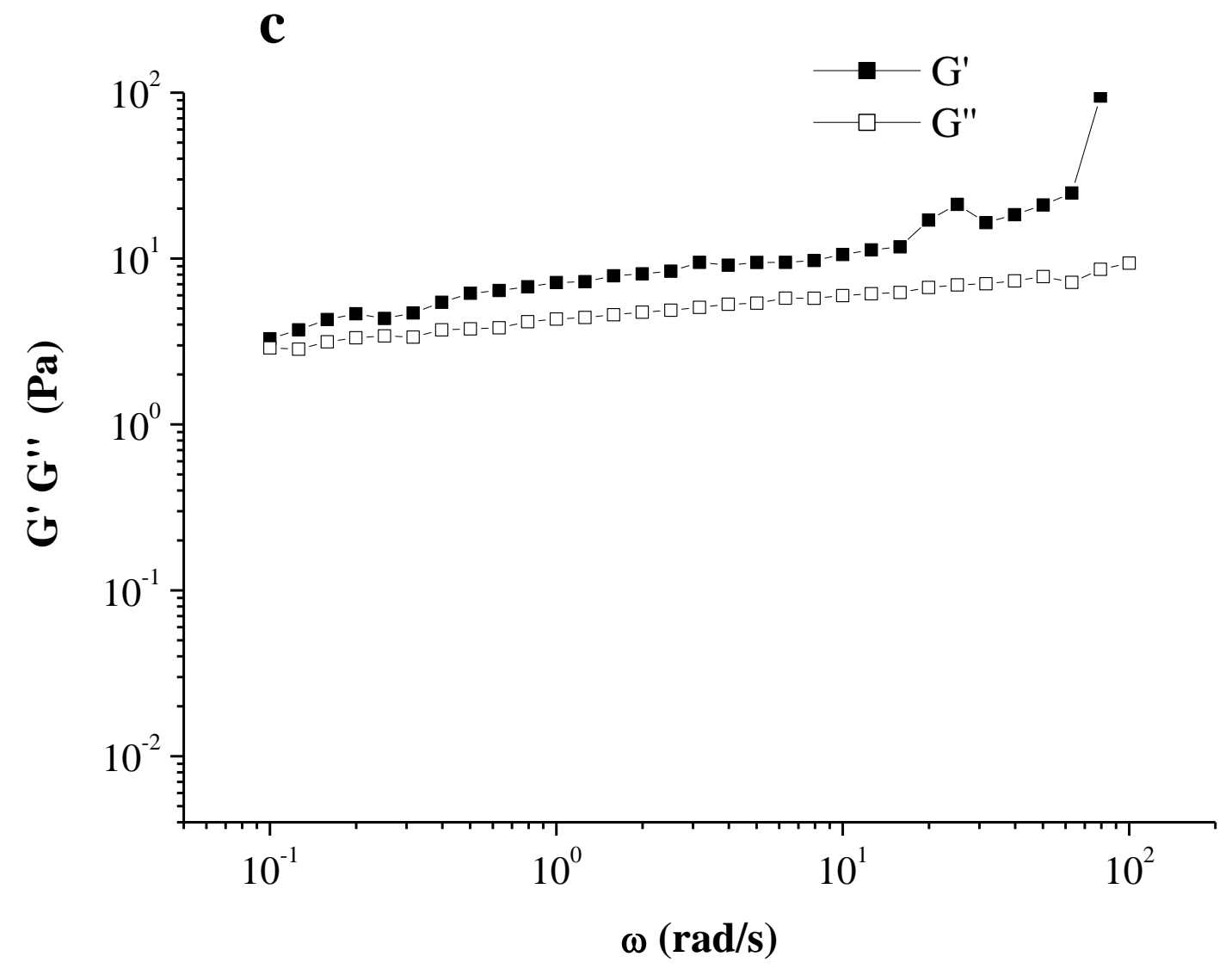




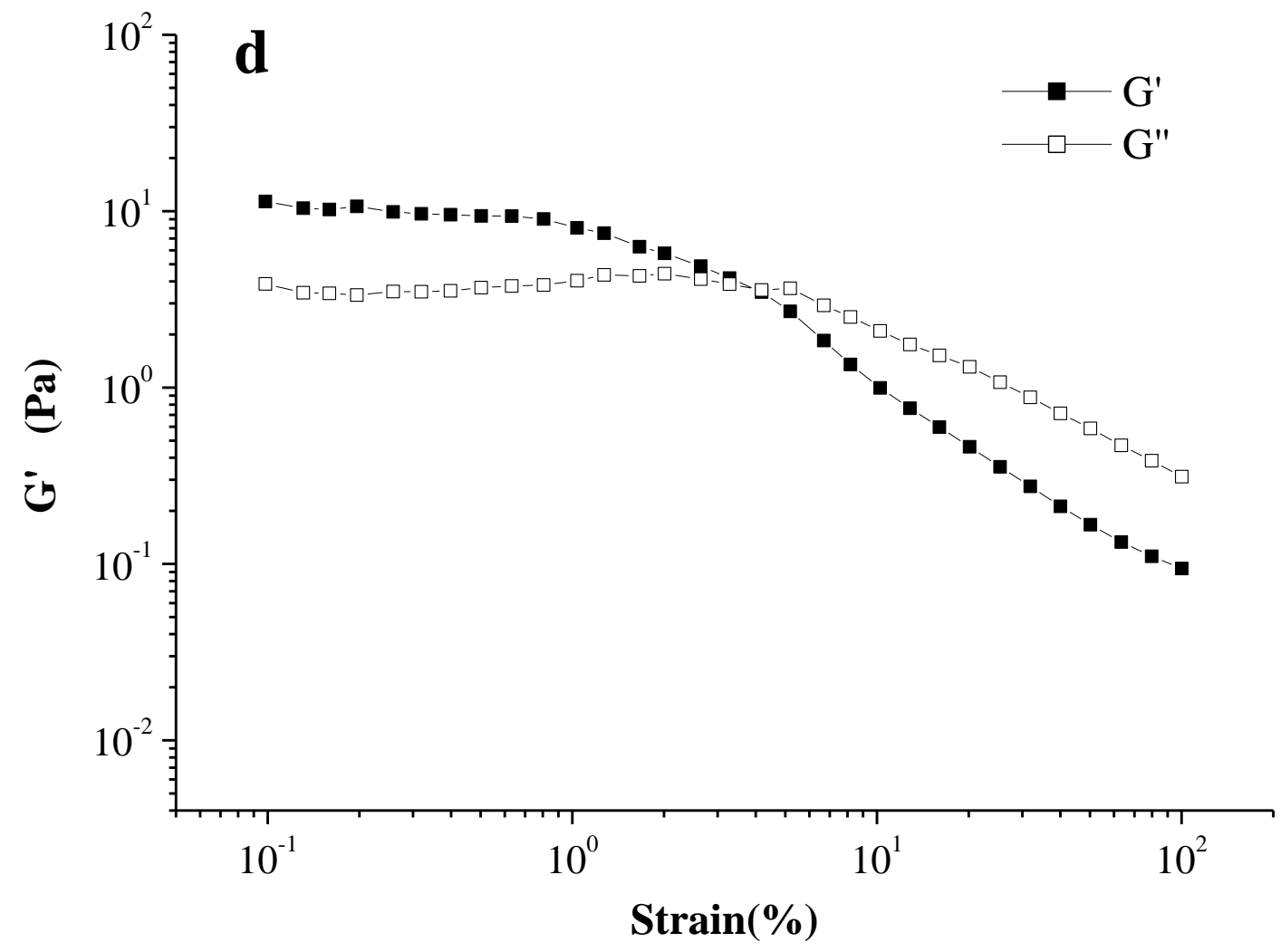


Fig. 5.

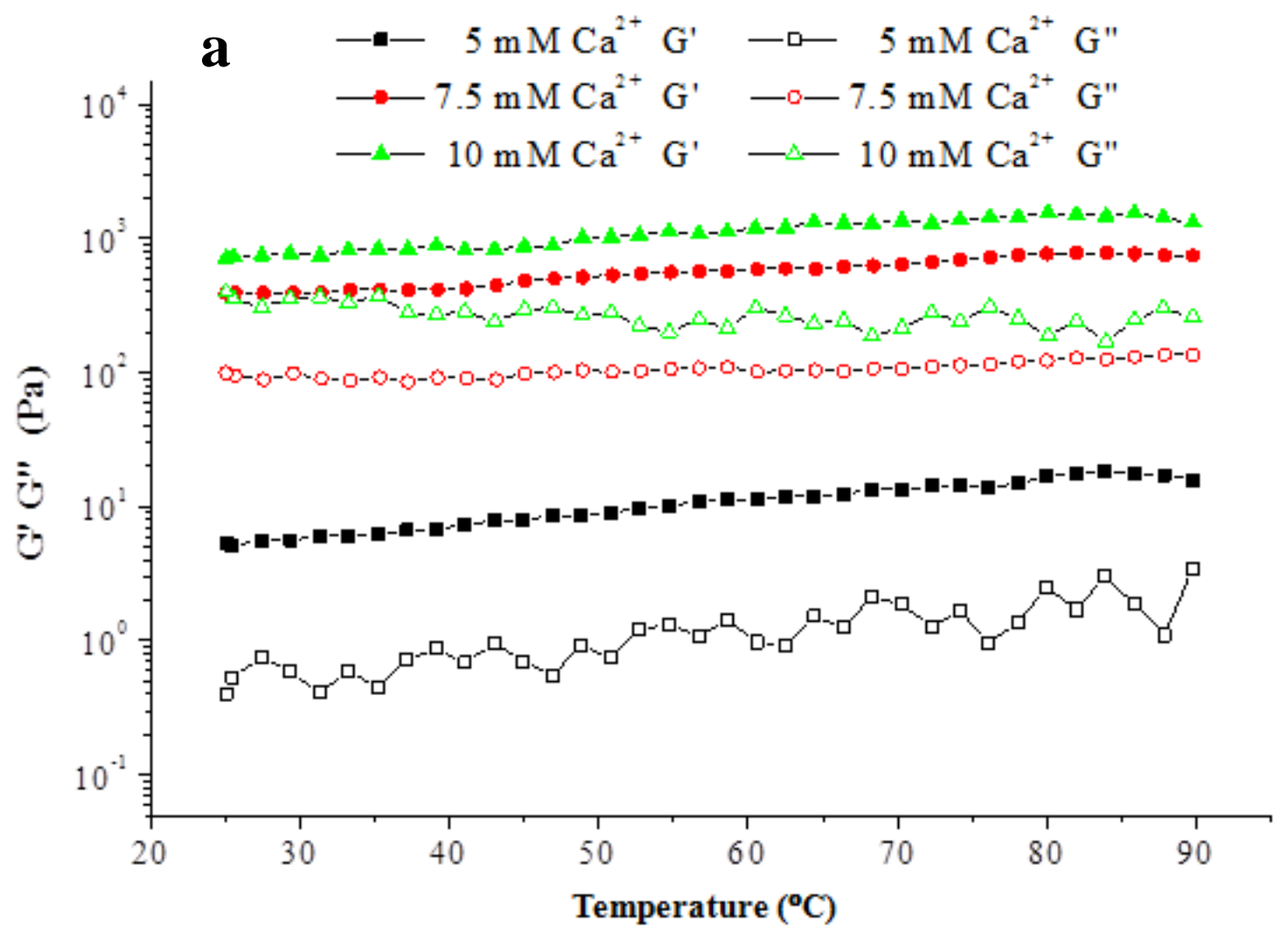




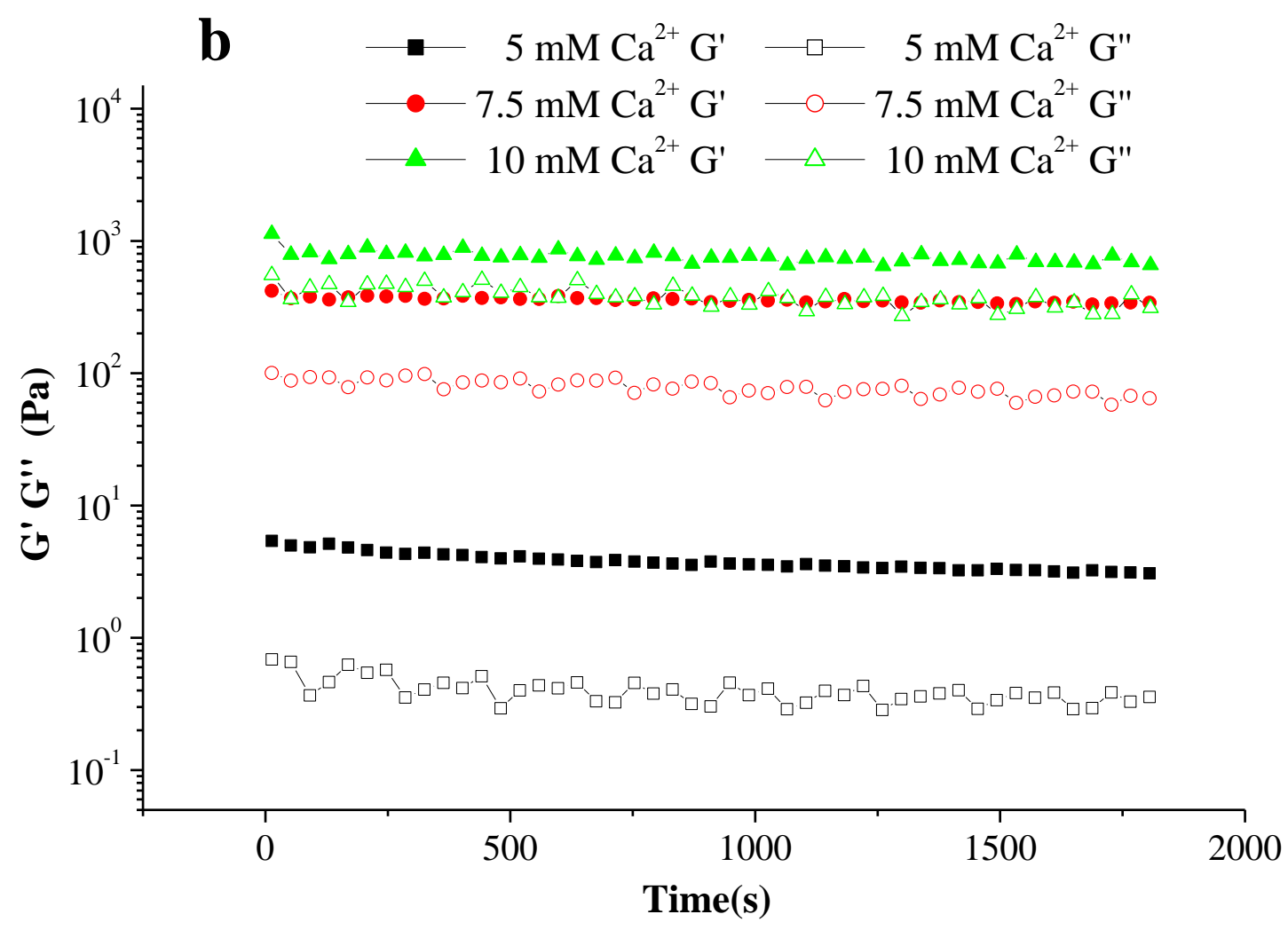




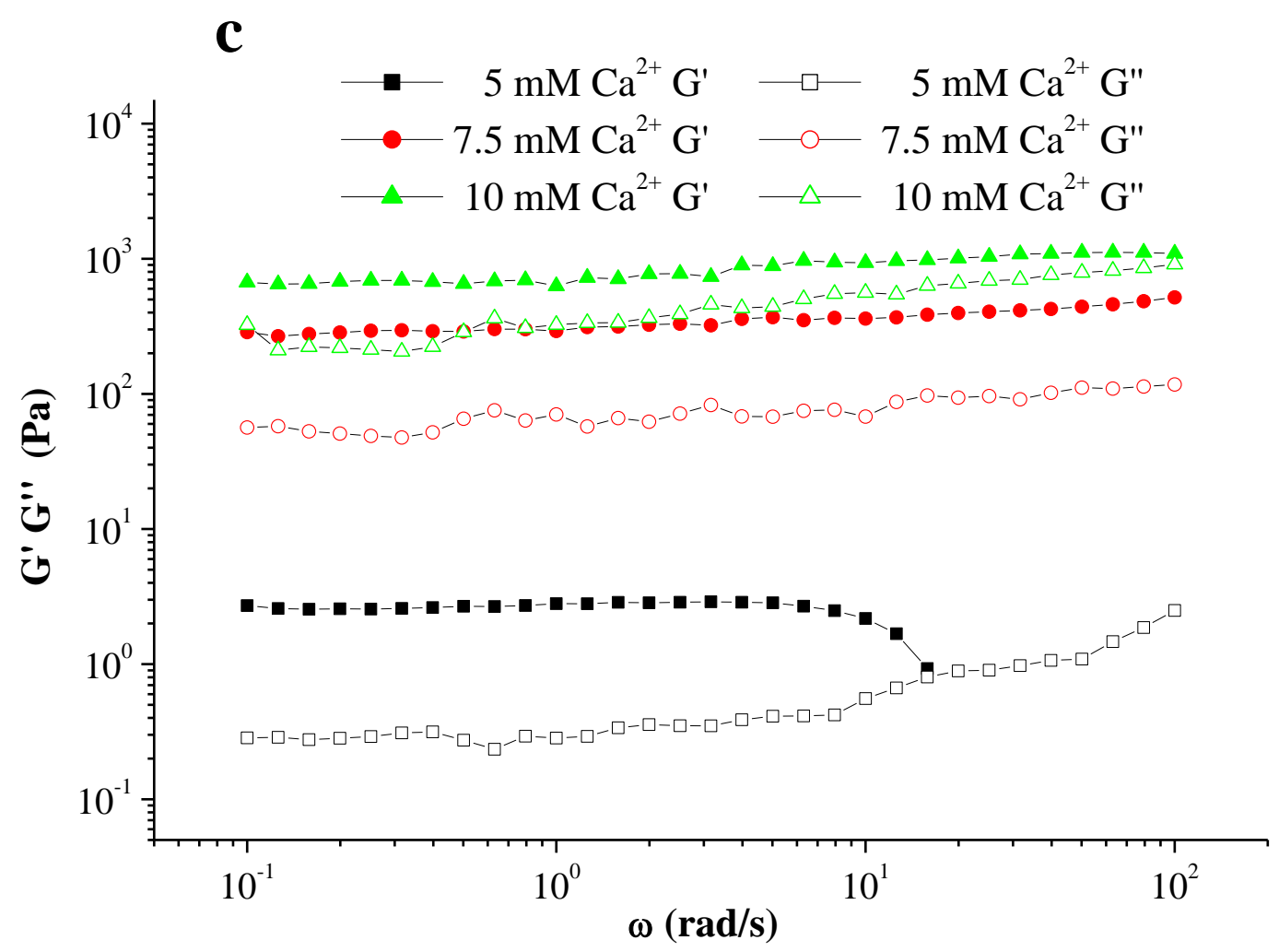




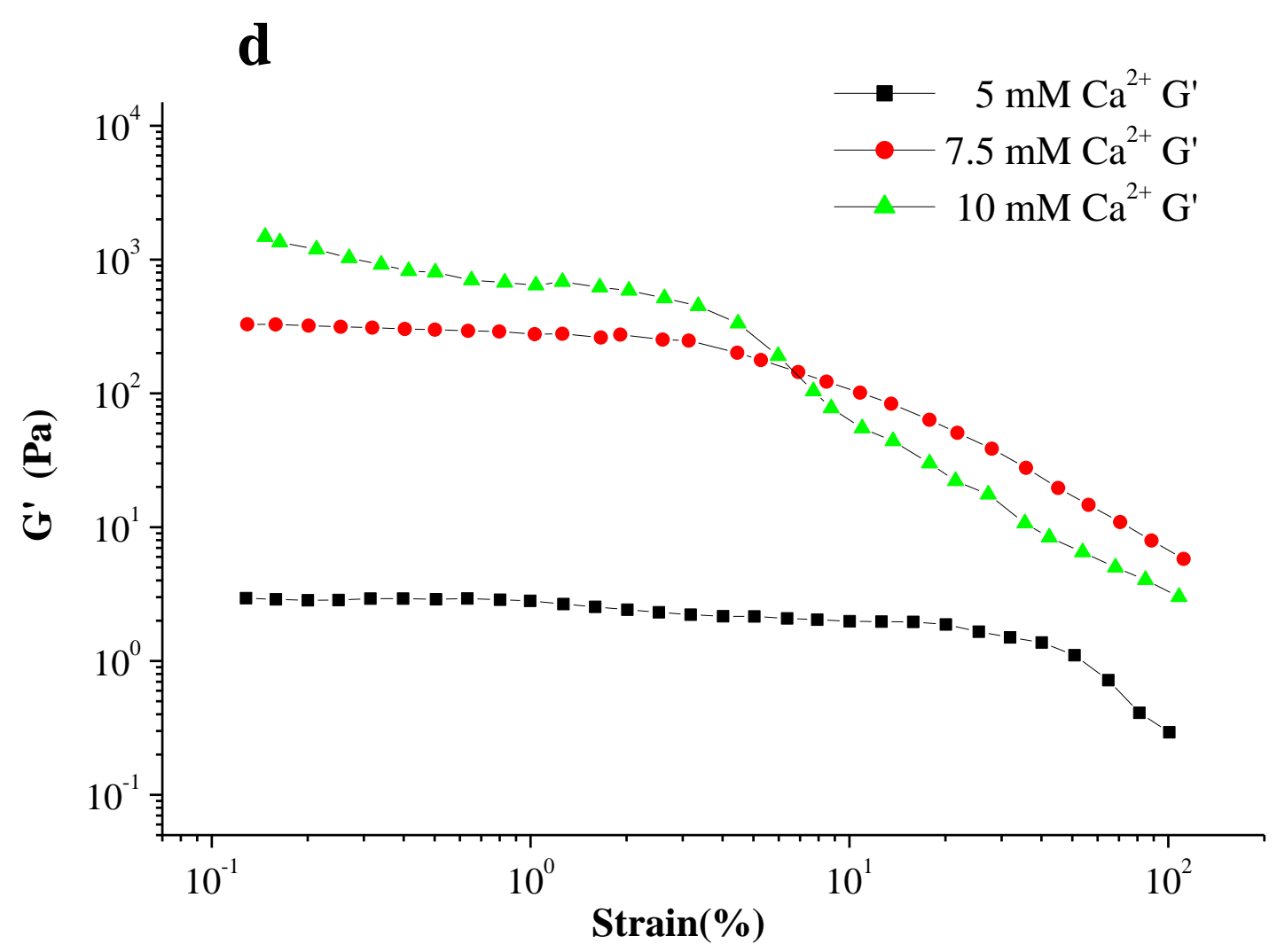


Fig. 6.

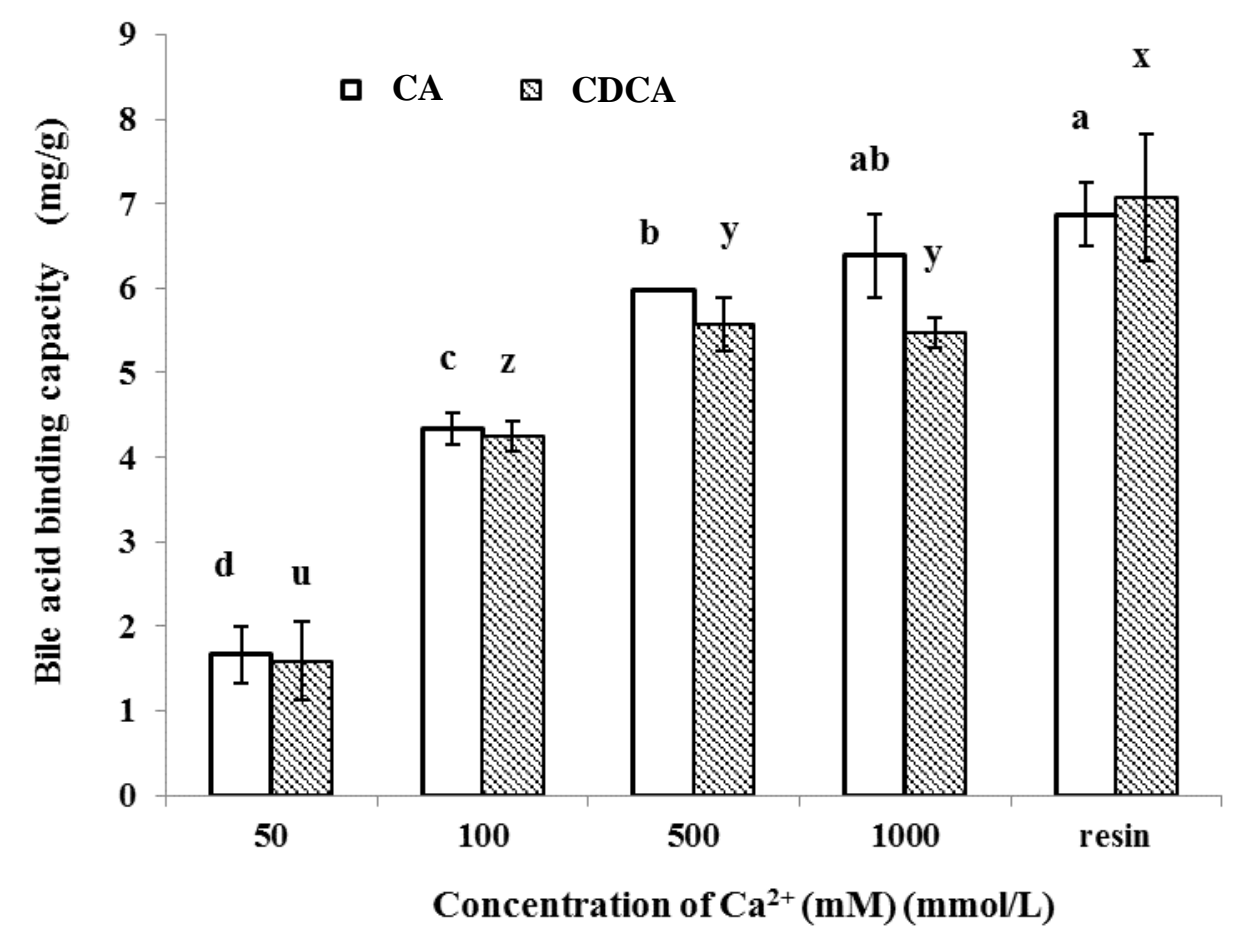




\section{Graphical abstract \\ 2 \\ 3}

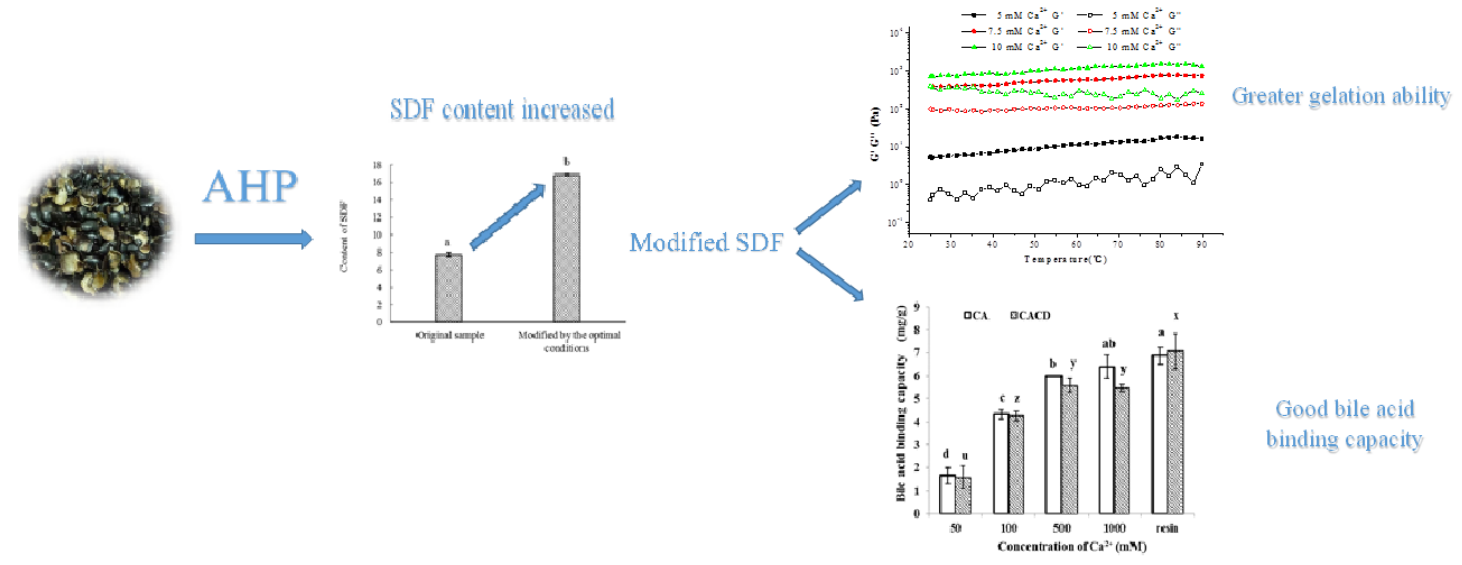

4

6 